\title{
A DESJUDICIALIZAÇÃO E A POSSIBILIDADE DE REALIZAÇÃO DO INVENTÁRIO EXTRAJUDICIAL MESMO COM A EXISTÊNCIA DE TESTAMENTO
}

\author{
Ana Elisa do Valle Mesquita Lomazini ${ }^{1}$ \\ Cláudio de Albuquerque Grandmaison ${ }^{2}$ \\ Júlio Cesar Franceschet ${ }^{3}$
}

\begin{abstract}
Resumo: O presente artigo tem por objetivos demonstrar como as serventias notariais constituem um importante mecanismo para a desjudicialização e trazer à tona discussões relacionadas ao inventário extrajudicial com a existência de testamento. Para tanto foi utilizada a pesquisa teórica, qualitativa, com objetivo exploratório, seguindo diretrizes do método indutivo, executada por meio de uma pesquisa de revisão de literatura e por uma pesquisa documental. Como resultado observou-se uma mudança de paradigma no sentido da possibilidade da realização do inventário extrajudicial mesmo com a existência de testamento, contribuindo para o movimento da desjudicialização.
\end{abstract}

\section{Palavras-chave: INVENTÁRIO EXTRAJUDICIAL; TESTAMENTO; SERVENTIAS} EXTRAJUDICIAIS.

\section{THE DEJUDICIALIZATION AND THE POSSIBILITY OF CARRYING OUT THE EXTRAJUDICIAL INVENTORY EVEN WITH THE EXISTENCE OF A WILL}

Abstract: The purpose of this article is to demonstrate how notarial services are an important mechanism for dejudicialization and to bring up discussions related to the extrajudicial inventory with the existence of a will. The theoretical and qualitative research was used for this purpose, with an exploratory objective, following the guidelines of the inductive method, carried out through a literature review and documentary research. As a result, there was a paradigm shift towards the possibility of carrying out the extrajudicial inventory even with the existence of a will, contributing to the dejudicialization movement.

\footnotetext{
${ }^{1}$ Mestranda em Direito e Gestão de Conflitos pela Universidade de Araraquara (UNIARA). Especialista em Direito Notarial e Registral pela Universidade Anhanguera-Uniderp e pela Faculdade Única de Ipatinga. Graduação em Direito pela Universidade Estadual Paulista (UNESP). Tabeliã de Protesto. E-mail: aemesquita@uol.com.br. Endereço postal: Rua Senador Bueno de Paiva, 188-A, Centro, Caldas/MG, CEP: 37.780000 .

${ }^{2}$ Mestrando Direito e Gestão de Conflitos pela Universidade de Araraquara (UNIARA). Especialista em Direito Civil e em Direito Empresarial pela UniFMU - Centro Universitário das Faculdades Metropolitanas Unidas. Especialista em Assessoria Parlamentar e Capacitação Política pela Fundação Escola de Sociologia e Política de São Paulo. Graduação em Direito pelas Faculdades Metropolitanas Unidas - FMU. Advogado/Assessor Especial Parlamentar. E-mail: adv.grandmaison @ gmail.com. Endereço postal: Av. Pedro Álvares Cabral, nº 201, sala 37 (Térreo), Moema, São Paulo/SP, CEP: 04.094-050.

${ }^{3}$ Doutor em Direito Civil pela Universidade de São Paulo (USP). Mestre em Direito Civil pela Universidade do Estado do Rio de Janeiro (UERJ). Graduado em Direito pela Universidade Federal de Viçosa (UFV). Professor dos cursos de graduação em Direito e Mestrado Profissional em Direito e Gestão de Conflitos da Universidade de Araraquara (UNIARA). Juiz de Direito. E-mail: jcfranceschet@uniara.edu.br. Endereço postal: Rua Tiradentes, $n^{\circ}$ 519, Centro, Ibitinga/SP, CEP: 14.940-000.
} 
Keywords: EXTRAJUDICIAL INVENTORY; TESTAMENT; EXTRAJUDICIAL SERVICES.

\section{INTRODUÇÃO}

Ante o crescente congestionamento do Poder Judiciário para solucionar as demandas a ele direcionadas, a desjudicialização é um fenômeno que ganha forças cada vez maiores não apenas no Brasil mas em todo o mundo, debruçando-se a doutrina e os Poderes Legislativo e Judiciário na sua expansão e aperfeiçoamento. Em meados da década de 1970, Mauro Cappelletti e Bryant Garth já abordavam em sua clássica obra "Acesso à Justiça” a evolução do conceito teórico de acesso à justiça, demonstrando que seu acesso não se restringia ao Poder Judiciário.

Como soluções práticas para enfrentar os problemas atinentes ao acesso efetivo à justiça, Cappelletti e Garth propuseram determinadas medidas denominadas "ondas renovatórias", dentre as quais destaca-se a "terceira onda", que "centra sua atenção no conjunto geral de instituições e mecanismos, pessoas e procedimentos utilizados para processar e mesmo prevenir disputas nas sociedades modernas" (CAPPELLETTI, 1988, p. 67 e 68). Desta forma, utilizando "mecanismos privados ou informais de solução de litígios" (CAPPELLETTI, 1988, p. 71), contexto no qual se inserem as serventias extrajudiciais no Brasil, o acesso à justiça foi ampliado para além do Poder Judiciário.

$\mathrm{Na}$ doutrina pátria, o Professor Kazuo Watanabe (2018), também trouxe uma atualização do conceito de acesso à justiça sob a denominação de acesso à "ordem jurídica justa", sustentando a existência de uma dimensão mais ampla do acesso à justiça, que não se limita ao acesso ao Poder Judiciário e abrange também as formas extrajudiciais de solução dos conflitos.

Frise-se que o movimento da desjudicialização, em razão de sua importância, é estimulado inclusive pelo Poder Judiciário, tanto que o Conselho Nacional de Justiça elencou como metas nacionais aprovadas pela Justiça Estadual para o ano de 2020, a meta de número 9, consistente em "realizar ações de prevenção ou desjudicialização de litígios voltadas aos objetivos de desenvolvimento sustentável (ODS), da Agenda 2030”.

A Agenda 2030, por sua vez, consiste em um plano de ação global organizado pelos cento e noventa e três países integrantes da Organização das Nações Unidas (ONU), com 17 objetivos de desenvolvimento sustentável e 169 metas, a serem implementados até 2030. 
Referidos objetivos mesclam as três dimensões do desenvolvimento sustentável: a econômica, a social e a ambiental. Assim, os temas tratados nos objetivos e metas são diversos, tais como a erradicação da pobreza, a redução das desigualdades sociais, questões climáticas, educação, crescimento econômico, dentre outros, com destaque, no presente artigo, para o $16^{\circ}$ OSD consistente em "paz, justiça e instituições eficazes". Para se alcançar tais objetivos foram traçadas metas e, dentre as metas relacionadas ao objetivo 16, três merecem destaque: 16.3 "Estado de Direito e acesso à justiça"; 16.6 - "Instituições eficazes, responsáveis e transparentes" e 16.7 - "Tomada de decisão responsiva, inclusiva, participativa e representativa".

Constata-se, assim, que a desjudicialização está em total sintonia com o movimento mundial da Agenda 2030, visando ampliar o acesso à justiça com a atuação de instituições não jurisdicionais eficazes para a solução de conflitos e a valorização de uma justiça inclusiva e participativa.

Neste contexto, o presente artigo visa analisar os requisitos que possibilitam a lavratura do inventário extrajudicial, com destaque para a decisão proferida pela $4^{\circ}$ Turma do STJ no julgamento do REsp no 1.808 .767 - RJ, em 15/10/2019, que fortalece uma mudança de paradigma ao entender pela possibilidade da realização de inventário extrajudicial mesmo com a existência de testamento do falecido, observadas determinadas condições. O objetivo será demonstrar como as serventias extrajudiciais constituem um importante mecanismo para a desjudicialização, constituindo um caminho adequado para a resolução de conflitos e prevenção de litígios.

Para a condução dos procedimentos necessários à realização dos objetivos definidos no parágrafo anterior, foi concebido um mapa metodológico explicitado nas seguintes configurações: pesquisa teórica, qualitativa, com objetivo exploratório, seguindo diretrizes do método indutivo, executada por meio de uma pesquisa de revisão de literatura e por uma pesquisa documental.

Já os resultados serão apresentados em outras seções que se complementam e proporcionam uma visão global da realidade estudada. Para tanto, após trazidas considerações sobre o papel das serventias extrajudiciais como instrumento de acesso à justiça e à ordem jurídica justa, adentrar-se-á na análise da possibilidade da lavratura de escritura pública de inventário extrajudicial mesmo com a existência de testamento do falecido. 
Referido entendimento configura uma mudança de paradigma trazida pela doutrina, pelas normativas das Corregedorias-Gerais de Justiça de alguns Estados e por enunciados de congressos reconhecidos, que culminaram no acórdão proferido pela $4^{\mathrm{a}}$ Turma do STJ, em decorrência do REsp no 1.808.767-RJ, julgado em 15/10/2019, de relatoria do Ministro Luís Felipe Salomão. Trata-se de um importante avanço no caminho da desjudicialização e ampliação do acesso à justiça, ante a controvérsia acerta da interpretação do artigo $610, \S^{\circ}$, do CPC.

\section{A DESJUDICIALIZAÇÃO E OS REQUISITOS DO INVENTÁRIO EXTRAJUDICIAL}

Nos dizeres de Silva e Tartuce,

de forma stricto sensu identifica-se a expressão "desjudicialização" como o termo empregado para caracterizar a alternativa de regularização de certas situações jurídicas em cartórios extrajudiciais.

As Serventias Extrajudiciais podem contribuir para a resolução de uma série de problemas ao conferir segurança jurídica às relações com maior celeridade e menor custo. Sua utilização restringe a intervenção do Estado na vida privada, favorecendo o exercício da cidadania e o fortalecimento da responsabilidade social (SILVA, 2016, p.05).

No Brasil diversas alterações legislativas possibilitaram a transferência de atividades, antes exclusivamente judiciais, para o âmbito extrajudicial.

Os registradores e tabeliães já vinham sendo chamados a atuar no relevante movimento da desjudicialização, ao passarem a realizar habilitação de casamento sem intervenção judicial (artigo 1526, CC/02), inventários, partilhas e divórcios consensuais (Lei Federal $\mathrm{n}^{\circ}$ 11.441/2007)17, registros tardios de nascimento sem intervenção judicial (Lei Federal no 11.790/08)18, divisão e demarcação de terras particulares (artigo 570, CPC/2015), homologação do penhor legal (artigo 703, $\S \S 2^{\circ}, 3^{\circ}$ e $4^{\circ}, C P C / 2015$ ), usucapião extrajudicial (artigo 216-A, Lei Federal $n^{\circ}$ 6.015/73), averbação direta de sentença estrangeira de divórcio puro no registro civil, com a dispensa da ação de homologação pelo STJ (artigo 961, §5, CPC/2015)19, reconhecimento espontâneo de paternidade/maternidade biológica (Provimento $n^{\circ} 16 / 2012$ do CNJ) e socioafetiva (Provimento $n^{\circ}$ 63/2017 do $\mathrm{CNJ}$ ), retificação administrativa de registro (artigo 110, Lei Federal $\mathrm{n}^{\circ}$ 6.015/73), averbação de alteração de prenome e gênero no registro civil em decorrência de transexualidade (Provimento $\mathrm{n}^{\circ}$ 73/2018 do CNJ), dentre outros" (HILL, 2018, p. 303).

Especial destaque merece a Lei 11.441/2007 que possibilitou a lavratura de inventário, partilha, separação consensual e divórcio consensual nos cartórios extrajudiciais, 
ao alterar o artigo 982 do Código de Processo Civil de 1973 (Lei 5.869/1973), atual artigo 610, caput e $\$ 1^{\circ}$, do Código de Processo Civil (Lei 13.105/2015), regulamentado pela Resolução 35/2007 do CNJ e pelas Corregedorias-Gerais de Justiça dos Estados, que detalharam o procedimento em seus respectivos Códigos de Normas das Serventias Notariais e de Registro.

Segundo levantamento da Associação dos Notários e Registradores do Brasil (ANOREG-BR), realizado em 2020, no período de janeiro de 2007 a setembro de 2020, foram realizados 1,5 milhão de inventários extrajudiciais nos Tabelionatos de Notas de todo o país. Os estados em que mais se realizaram escrituras públicas de inventário extrajudicial foram São Paulo (583.103), Rio Grande do Sul (185.637) e Paraná (184.356) (ANOREG-BR, 2020, p. 56 e 57$)$.

A atuação notarial nos atos da Lei 11.441/2007 resultou na facilitação e otimização de tempo para o cidadão e para o Poder Judiciário, além de gerar uma economia de quase $\mathrm{R} \$ 5$ bilhões para os cofres públicos (até 2018), beneficiando mais de 8 milhões de pessoas (ANOREG-BR, 2020, p. 45).

A Lei 11.441/2007, responsável por introduzir a possibilidade da realização do inventário extrajudicial nas serventias notariais, alterou o artigo 982 do Código de Processo Civil de 1973, que passou a ter a seguinte redação:

Art. 982. Havendo testamento ou interessado incapaz, proceder-se-á ao inventário judicial; se todos forem capazes e concordes, poderá fazer-se o inventário e a partilha por escritura pública, a qual constituirá título hábil para o registro imobiliário.

Parágrafo único. O tabelião somente lavrará a escritura pública se todas as partes interessadas estiverem assistidas por advogado comum ou advogados de cada uma delas, cuja qualificação e assinatura constarão do ato notarial.

Na sequência, a Resolução 35/2007 do Conselho Nacional de Justiça (CNJ) disciplinou a lavratura das escrituras públicas de inventário, partilha, separação consensual, divórcio consensual e extinção consensual de união estável realizadas nas serventias notariais, a fim de uniformizar o procedimento em todo território nacional.

Assim, a normativa do $\mathrm{CNJ}$ esclareceu diversos pontos fundamentais relacionados à lavratura de tais atos notariais como a livre escolha, pelas partes, do cartório de notas onde 
será realizada a escritura ${ }^{4}$; a faculdade concedida às partes de optar entre a via judicial ou extrajudicial $^{5}$; o enaltecimento de que tais escrituras públicas não dependem de homologação judicial e são títulos hábeis para os registros civil e imobiliário, bastando, por si só, para a efetivação de quaisquer transferências de bens móveis ou imóveis ${ }^{6}$; a presença obrigatória de advogado ou defensor público no ato notarial ${ }^{7}$, dentre outras questões importantes para a efetivação de referidos procedimentos extrajudiciais.

Constata-se, pela análise da Resolução 35/2007 do CNJ, que os requisitos necessários para a lavratura do inventário extrajudicial não estão consolidados em um único dispositivo. Ao contrário, estão dispersos em vários artigos componentes da normativa, tais como os artigos 11, 15, 17, 20, 21, 22, 23, 24 e 29.

No que tange à existência ou não de testamento do falecido, apenas o artigo 21, ao tratar dos itens obrigatórios a serem mencionados na escritura pública de inventário e partilha, exige a "menção ou declaração dos herdeiros de que o autor da herança não deixou testamento" sob as penas da lei ${ }^{8}$.

Atualmente o Código de Processo Civil (Lei 13.105/2015), em substituição ao artigo 982 do Código Processual anterior, dispõe:

Art. 610. Havendo testamento ou interessado incapaz, proceder-se-á ao inventário judicial.

$\S 1^{\circ}$ Se todos forem capazes e concordes, o inventário e a partilha poderão ser feitos por escritura pública, a qual constituirá documento hábil para

\footnotetext{
${ }^{4}$ Art. $1^{\circ}$ Para a lavratura dos atos notariais relacionados a inventário, partilha, separação consensual, divórcio consensual e extinção consensual de união estável por via administrativa, é livre a escolha do tabelião de notas, não se aplicando as regras de competência do Código de Processo Civil (Redação dada pela Resolução n ${ }^{\circ} 326$, de 26.6.2020).

${ }^{5}$ Art. $2^{\circ}$ É facultada aos interessados a opção pela via judicial ou extrajudicial; podendo ser solicitada, a qualquer momento, a suspensão, pelo prazo de 30 dias, ou a desistência da via judicial, para promoção da via extrajudicial.

${ }^{6}$ Art. $3^{\circ}$ As escrituras públicas de inventário e partilha, separação e divórcio consensuais não dependem de homologação judicial e são títulos hábeis para o registro civil e o registro imobiliário, para a transferência de bens e direitos, bem como para promoção de todos os atos necessários à materialização das transferências de bens e levantamento de valores (DETRAN, Junta Comercial, Registro Civil de Pessoas Jurídicas, instituições financeiras, companhias telefônicas etc).

${ }^{7}$ Art. $8^{\circ}$ É necessária a presença do advogado, dispensada a procuração, ou do defensor público, na lavratura das escrituras aqui referidas, nelas constando seu nome e registro na OAB. (Redação dada pela Resolução no 326 , de 26.6.2020)

${ }^{8}$ Art. 21. A escritura pública de inventário e partilha conterá a qualificação completa do autor da herança; o regime de bens do casamento; pacto antenupcial e seu registro imobiliário, se houver; dia e lugar em que faleceu o autor da herança; data da expedição da certidão de óbito; livro, folha, número do termo e unidade de serviço em que consta o registro do óbito; e a menção ou declaração dos herdeiros de que o autor da herança não deixou testamento e outros herdeiros, sob as penas da lei.
} 
qualquer ato de registro, bem como para levantamento de importância depositada em instituições financeiras.

$\S 2{ }^{\circ} \mathrm{O}$ tabelião somente lavrará a escritura pública se todas as partes interessadas estiverem assistidas por advogado ou por defensor público, cuja qualificação e assinatura constarão do ato notarial.

Em virtude de tais dispositivos legais, a doutrina e jurisprudência indicavam como requisitos para a lavratura do inventário extrajudicial a existência de sucessores capazes e concordes e a inexistência de testamento deixado pelo falecido.

Consoante mencionado por Carneiro:

O artigo 610, caput, $\S \S 1^{\circ}$ e $2^{\circ}$, do novo CPC, na linha do que já estabelecia o artigo 982 do CPC de 1973, com a redação dada pela Lei $\mathrm{n}^{\circ}$ 11.441/2007, define os requisitos para possibilitar que os interessados optem pela via extrajudicial, a saber:

- As partes forem todas maiores e capazes;

- Houver acordo de partilha;

- Estiver presente um advogado para assistência das partes;

- Não houver testamento (CARNEIRO, 2019, p. 238).

Desta forma, a simples existência de um testamento, em qualquer de suas modalidades, configurava um empecilho à utilização deste célere e eficaz mecanismo extrajudicial de realização do inventário e partilha pela via administrativa, já que, nesta hipótese, as partes eram obrigadas a realizar o inventário judicial.

\section{A MUDANÇA DE PARADIGMA E O ACÓRDÃO DECORRENTE DO RESP No}

\subsubsection{7-RJ}

Ocorre que uma mudança de paradigma começou a ganhar força na doutrina pátria, acompanhada de normativas de Corregedorias-Gerais de Justiça de alguns Estados em seus respectivos Códigos de Normas das Serventias Extrajudiciais, culminando no importante acórdão decorrente do REsp n ${ }^{\circ}$ 1.808.767-RJ, julgado em 15/10/2019, pela $4^{\text {a }}$ Turma do STJ, cuja ementa segue transcrita:

RECURSO ESPECIAL. CIVIL E PROCESSO CIVIL. SUCESSÕES.EXISTENNCIA DE TESTAMENTO. INVENTÁRIO EXTRAJUDICIAL. POSSIBILIDADE, DESDE QUE OS INTERESSADOS SEJAM MAIORES, CAPAZES E CONCORDES, DEVIDAMENTE ACOMPANHADOS DE SEUS ADVOGADOS. ENTENDIMENTO DOS ENUNCIADOS 600 DA VII JORNADA DE 
DIREITO CIVIL DO CJF; 77 DA I JORNADA SOBREPREVENÇÃO E SOLUÇÃO EXTRAJUDICIAL DE LITÍGIOS; 51 DA I JORNADA DE DIREITO PROCESSUAL CIVIL DO CJF; E 16 DO IBDFAM.

1. Segundo o art. 610 do CPC/2015 (art. 982 do CPC/73), em havendo testamento ou interessado incapaz, proceder-se-á ao inventário judicial. Em exceção ao caput, o $\S 1^{\circ}$ estabelece, sem restrição, que, se todos os interessados forem capazes e concordes, o inventário e a partilha poderão ser feitos por escritura pública, a qual constituirá documento hábil para qualquer ato de registro, bem como para levantamento de importância depositada em instituições financeiras.

2. O Código Civil, por sua vez, autoriza expressamente, independentemente da existência de testamento, que, "se os herdeiros forem capazes, poderão fazer partilha amigável, por escritura pública, termo nos autos do inventário, ou escrito particular, homologado pelo juiz" (art. 2.015). Por outro lado, determina que "será sempre judicial a partilha, se os herdeiros divergirem, assim como se algum deles for incapaz" (art. 2.016) - bastará, nesses casos, a homologação judicial posterior do acordado, nos termos do art. 659 do CPC.

3. Assim, de uma leitura sistemática do caput e do $\S 1^{\circ}$ do art. 610 do CPC/2015, c/c os arts. 2.015 e 2.016 do CC/2002, mostra-se possível o inventário extrajudicial, ainda que exista testamento, se os interessados forem capazes e concordes e estiverem assistidos por advogado, desde que o testamento tenha sido previamente registrado judicialmente ou haja a expressa autorização do juízo competente.

4. A mens legis que autorizou o inventário extrajudicial foi justamente a de desafogar o Judiciário, afastando a via judicial de processos nos quais não se necessita da chancela judicial, assegurando solução mais célere e efetiva em relação ao interesse das partes. Deveras, o processo deve ser um meio, e não um entrave, para a realização do direito. Se a via judicial é prescindível, não há razoabilidade em proibir, na ausência de conflito de interesses, que herdeiros, maiores e capazes, socorram-se da via administrativa para dar efetividade a um testamento já tido como válido pela Justiça.

5. Na hipótese, quanto à parte disponível da herança, verifica-se que todos os herdeiros são maiores, com interesses harmoniosos e concordes, devidamente representados por advogado. Ademais, não há maiores complexidades decorrentes do testamento. Tanto a Fazenda estadual como o Ministério Público atuante junto ao Tribunal local concordaram com a medida. Somado a isso, o testamento público, outorgado em 2/3/2010 e lavrado no $18^{\circ}$ Ofício de Notas da Comarca da Capital, foi devidamente aberto, processado e concluído perante a $2^{\mathrm{a}}$ Vara de Órfãos e Sucessões.

6. Recurso especial provido.

Em seu voto, que foi acompanhado por unanimidade pelos demais julgadores, o relator Ministro Luís Felipe Salomão salientou a controvérsia existente acerca da possibilidade de realização do inventário extrajudicial quando há testamento do falecido, especialmente quando os sucessores são capazes e concordes. A decisão do Tribunal de origem havia julgado, por maioria, pela impossibilidade da realização do inventário 
extrajudicial em razão da existência de testamento, com fundamento no $\operatorname{artigo~} 610, \S 1^{\circ}$, do CPC.

Todavia, o Ministro Luís Felipe Salomão, ao analisar o artigo 610 e seu $§ 1^{\circ}$, trouxe fundamentos da técnica legislativa para alterar a interpretação anteriormente dada a referido dispositivo legal, asseverando que o $\S 1^{\circ}$ traz, na realidade, uma exceção ao caput do artigo 610. Assim salientou:

Decorrente da própria técnica legislativa, o caput do dispositivo de lei deve ser tido como o responsável pela ideia central do artigo, cabendo aos parágrafos a definição dos seus desdobramentos, explicações, complementações, condições e exceções à cabeça do dispositivo.

Com efeito, "os parágrafos têm por finalidade explicar ou modificar a regra constante do artigo ao qual se submetem. Possuem função de escrita secundária e não devem estabelecer regra geral. As alíneas, incisos e itens devem ter apenas uma função esclarecedora ou enunciativa" (VENOSA, Sílvio de Salvo. Introdução ao estudo do direito: primeiras linhas. São Paulo: Atlas, 2006, p. 209).

Nessa ordem de ideias, o caput do art. 610 estabelece a regra: em havendo testamento ou interessado incapaz, o inventário se dará pela via judicial. Não obstante, conforme exceção à regra disposta no $\S 1^{\circ}$, o inventário e a partilha poderão ser feitos por escritura pública sempre que os herdeiros forem capazes e concordes e não façam nenhuma restrição, o que engloba, por óbvio, a situação em que exista testamento.

Também trouxe à baila os artigos 2015 e 2016 do Código Civil que dispõem sobre o inventário por escritura pública sem condicionar à inexistência de testamento, bastando os herdeiros serem capazes e estarem concordes com os termos da partilha:

Art. 2015. Se os herdeiros forem capazes, poderão fazer partilha amigável, por escritura pública, termo nos autos do inventário, ou escrito particular, homologado pelo juiz.

Art. 2016. Será sempre judicial a partilha, se os herdeiros divergirem, assim como se algum deles for incapaz.

Por meio de uma interpretação sistemática e coerente do ordenamento jurídico, o Ministro Luís Felipe Salomão ainda conjugou aos dispositivos legais acima citados o artigo $5^{\circ}$ da Lei de Introdução às Normas do Direito Brasileiro (LINDB) e os arts. $3^{\circ}, \S 2^{\circ}, 4^{\circ}$ e $8^{\circ}$ do CPC, justificando que "os fins sociais e as exigências do bem comum em relação à norma autorizadora de inventário extrajudicial são a redução de formalidades e burocracias, com o 
incremento do maior número de procedimentos e de solução de controvérsias por meios alternativos ao aparato estatal". Ao fim concluiu:

Assim, de uma leitura sistemática do caput e do $\S 1^{\circ}$ do art. 610 , do CPC/2015, penso ser possível o inventário extrajudicial, ainda que exista testamento, se os interessados forem capazes e concordes e estiverem assistidos por advogado, desde que o testamento tenha sido previamente registrado judicialmente ou haja a expressa autorização do juízo competente.

Trata-se de uma mudança de paradigma que tem sido cada vez mais consolidada e divulgada, tendo, inclusive, sido objeto de diversos enunciados. O primeiro Enunciado do Colégio Notarial do Brasil, aprovado no XIX Congresso Brasileiro de Direito Notarial e Registral, dispôs que "é possível o inventário extrajudicial ainda que haja testamento, desde que previamente registrado em Juízo ou homologado posteriormente perante o Juízo competente" (COLÉGIO NOTARIAL DO BRASIL, 2014).

Na sequência, o tema também foi abordado na VII Jornada de Direito Civil do Conselho da Justiça Federal, cujo Enunciado n. 600 previu que "após registrado judicialmente o testamento e sendo todos os interessados capazes e concordes com os seus termos, não havendo conflito de interesses, é possível que se faça o inventário extrajudicial" ${ }^{9}$ (CONSELHO DA JUSTIÇA FEDERAL, 2015). No mesmo ano, no X Congresso Brasileiro de Direito de Família, também foi aprovado o Enunciado n. 16 do Instituto Brasileiro de Direito de Família (IBDFAM), segundo o qual "mesmo quando houver testamento, sendo todos os interessados capazes e concordes com os seus termos, não havendo conflito de interesses, é possível que se faça o inventário extrajudicial" (IBDFAM, 2015).

No ano subsequente, destaca-se que o assunto veio novamente à tona na I Jornada sobre Prevenção e Solução Extrajudicial de Litígios, organizada pelo Centro de Estudos Judiciários do Conselho da Justiça Federal, da qual resultou o Enunciado n. 77, que dispõe

\footnotetext{
${ }^{9}$ Justificativa do Enunciado 600 da VII Jornada de Direito Civil do CJF: "A só existência de testamento não serve de justificativa para impedir que o inventário seja levado a efeito extrajudicialmente. Muitas vezes, as disposições testamentárias não têm natureza patrimonial. Em outros casos, claros são os seus termos, não ensejando qualquer dúvida dos herdeiros e dos beneficiados quanto à última manifestação de vontade. Inclusive muitos juízes, quando do registro do testamento, têm autorizado o uso da via extrajudicial, sem que tal afete a higidez do procedimento levado a efeito perante o tabelião. A Justiça paulista foi a pioneira, tendo a Corregedoria Permanente se manifestado favoravelmente a esta prática. De qualquer modo, persiste a possibilidade de serem discutidas, na via judicial, eventuais controvérsias sobre a validade do testamento ou de alguma de suas cláusulas. Certamente esta é uma medida para desafogar a já tão congestionada Justiça, não envolvendo os magistrados em processo no qual nada têm a decidir, além de assegurar às partes uma solução mais rápida a uma questão que não necessita da chancela judicial."
} 
"havendo registro ou expressa autorização do juízo sucessório competente, nos autos do procedimento de abertura e cumprimento de testamento, sendo todos os interessados capazes e concordes, o inventário e partilha poderão ser feitos por escritura pública, mediante acordo dos interessados, como forma de pôr fim ao procedimento judicial" (CONSELHO DA JUSTIÇA FEDERAL, 2016).

Por fim, em 2017, o tema foi novamente abordado pelo Conselho da Justiça Federal, mas na I Jornada de Direito Processual Civil, resultando no Enunciado n. 51 que estabeleceu "havendo registro judicial ou autorização expressa do juízo sucessório competente, nos autos do procedimento de abertura, registro e cumprimento de testamento, sendo todos os interessados capazes e concordes, poderão ser feitos o inventário e a partilha por escritura pública" (CONSELHO DA JUSTIÇA FEDERAL, 2017).

Referido entendimento também tem sido adotado pelas Corregedorias-Gerais de Justiça de alguns Estados, as quais previram expressamente em suas normativas aplicáveis às serventias extrajudiciais a possibilidade de realização do inventário extrajudicial mesmo com a existência de testamento do falecido. Conforme citado pelo Ministro Luís Felipe Salomão em seu voto:

Ademais, já é a realidade adotada pelas Corregedorias dos Tribunais do país, que vêm autorizando o inventário extrajudicial, ainda que presente disposição de última vontade (testamento), desde que os interessados sejam capazes e concordes, como soem, por exemplo, as determinações do TJSP (Provimento n. 37 da Corregedoria-Geral), do TJRJ (nova redação do art. 297, § $1^{\circ}$, da Consolidação Normativa da Corregedoria-Geral - Provimento n. 21/2017), do TJPB (art. 310 do Código Geral de Normas Judicial e Extrajudicial da Corregedoria-Geral do Tribunal de Justiça do Estado da Paraíba) e do TJPR (Ofício-circular 155/2018 da Corregedoria da Justiça do Paraná).

Acrescente-se a estas, as Corregedorias do TJMS (Provimento 165) e do TJMG (art. 224, §1 ${ }^{\circ}$, do Provimento Conjunto 93/2020).

Frise-se que a doutrina especializada também partilha do entendimento pela possibilidade da lavratura do inventário extrajudicial mesmo com a existência de testamento 
do falecido, alinhada ao movimento da desjudicialização e ao desiderato de ampliação do acesso à justiça. ${ }^{10}$

$\mathrm{O}$ advento da Lei $\mathrm{n}^{\mathrm{o}} 11.441 / 07$ permitiu a realização de inventários e partilhas com agilidade e segurança jurídica pelos Tabeliães de todo o Brasil, contribuindo para a desburocratização de procedimentos. Seria oportuna a ampliação desses atos também nas hipóteses em que o autor da herança tivesse deixado testamento ou herdeiro incapaz, desde que existisse consenso entre os herdeiros. Nesses casos, o ato notarial poderia contar com a aquiescência do Ministério Público para a cautela dos interesses indisponíveis envolvidos.

(...) As limitações previstas na Lei $\mathrm{n}^{\mathrm{o}} 11.441 / 07$ procuravam resguardar direitos indisponíveis: o cumprimento das disposições de última vontade do

\footnotetext{
${ }^{10}$ Em seu voto o Ministro Luís Felipe Salomão cita Maria Helena Diniz, Flávio Tartuce, Zeno Veloso e Arnaldo Rizzardo (REsp no ${ }^{\circ}$.808.767-RJ, $4^{\text {a }}$ Turma do STJ):

Se houver testamento com conteúdo patrimonial, pode-se fazer partilha por escritura pública se herdeiros forem capazes, seguida de homologação judicial. É possível o inventário extrajudicial ainda que haja testamento, desde que previamente registrado em juízo ou homologado posteriormente pelo juízo competente (Enunciado $\mathrm{n}$. 1do Colégio Notarial do Brasil) [...] Realmente, a existência de testamento não deveria coibir inventário extrajudicial, desde que haja: a) homologação judicial do ato de última vontade; b) plena capacidade dos herdeiros; c) ausência de conflito entre os interessados; e d) invocação da cláusula geral de negócios processuais atípicos (CPC, art. 190).(DINIZ, Maria Helena. Curso de direito civil: vol. 6: direito das sucessões. São Paulo: Saraiva, 2019, p. 446).
}

Com o devido respeito, os diplomas legais que exigem a inexistência de testamento para que a via administrativa do inventário seja possível devem ser mitigados, especialmente nos casos em que os herdeiros são maiores, capazes e concordam com esse caminho facilitado. Nos termos do art. $5^{\circ}$ da Lei de Introdução, o fim social da Lei 11.441/2007 foi a redução de formalidades, devendo essa sua finalidade sempre guiar o intérprete do Direito. O mesmo deve ser dito quanto ao Novo CPC, inspirado pelas máximas de desjudicialização e de celeridade (TARTUCE, Flávio. Direito Civil: direito das sucessões, Vol. 6, Rio de Janeiro: Forense, 2018, p. 548).

Nos termos da Lei $^{\circ}{ }^{\circ} 11.441 / 07$, o inventário e partilha por escritura pública só podem ser feitos se todos os interessados forem capazes e concordes, devendo estar assistidos por advogado. Mas a utilização deste expediente extrajudicial, não pode ocorrer se o falecido deixou testamento. Não importa a forma do testamento ordinário ou especial - ou da natureza das disposições testamentárias, ou de o testamento já ter sido registrado ou confirmado em juízo e com o 'cumpra-se' do juiz (CPC, arts. 1.125 a 1.134). Dada a expressa vedação legal, não há como fugir à conclusão de que a existência do testamento impede a utilização da partilha extrajudicial. Mas, se os herdeiros forem capazes, poderão fazer partilha amigável, por escritura pública, na forma do art. 2.015 do Código Civil, mesmo que o autor da herança tenha deixado testamento, todavia, como prevê o art. 1.0131 do CPC [art. 659 do novo CPC] - com a redação dada pelo art. $2^{\circ}$ da Lei $n^{\circ} 11.441 / 07$-, a partilha, neste caso, tem de ser homologada pelo juiz. Entretanto, o falecido pode ter morrido sem testamento, mas ter deixado um codicilo(Código Civil, art. 1.881), que é disposição de última vontade, de conteúdo e objeto limitados, e testamento não é. Penso que, neste caso, é possível fazer-se a partilha extrajudicial, por escritura pública.(cf. Juliana da Fonseca Bonates, Separação, divórcio, partilhas e inventários extrajudiciais, coordenadores Antônio Carlos Mathias Coltro e Mário Luiz Delgado, São Paulo: Editora Método, 007, p. 318).(VELOSO, ZENO. Lei $n^{\circ}$ 11.441, de 04.01.2007 - Aspectos práticos da separação, divórcio, inventário e partilha consensuais. In: Família e responsabilidade. Coord. Rodrigo da Cunha Pereira. Porto Alegre: Magister/IBDFAM, 2010, p. 114).

Unicamente quando da existência de testamento, ou de incapazes, ou de falta de acordo, é obrigatória a via judicial. Na existência de testamento, entretanto, passou a entender-se a possibilidade da escritura pública, bastando, em passo posterior, a mera homologação do juiz (RIZZARDO, Arnaldo. Direito das sucessões. Rio de Janeiro: Forense, 2018, p. 604).

Revista de Direito de Família e Sucessão | e-ISSN: 2526-0227 | Encontro Virtual | v. 7 | n. 1 | p. $57-74$ | Jan/Jul. 2021. 
testador e os interesses de menores-herdeiros ou legatários e a disposição que determina a criação de fundação, situações que são fiscalizadas pelo Ministério Público. Parece incoerente que o Tabelião, mesmo possuindo fé pública para a lavratura ou aprovação do testamento (nos termos do art. 1.864 do Código Civil), não seja reputado apto a dar fiel cumprimento a ele (SILVA, 2016, p.14).

Carneiro também enfatiza que o artigo 610 do CPC deve ser interpretado com cautela:

Não existe nenhuma incompatibilidade lógica para a realização do inventário extrajudicial com a existência de um testamento. Nem sequer há de falar-se em ato jurídico viciado ou inválido.

O que é necessário, sim, é que o testamento seja apresentado e processado em juízo e o seu cumprimento pode se dar por meio de escritura pública que deverá ser levada, posteriormente, para o juízo onde se processou o testamento de sorte a demonstrar que as suas cláusulas foram efetivamente observadas, não só pelo órgão do Ministério Público, cuja intervenção é obrigatória, como também do próprio juízo. Não há que se falar em qualquer tipo de prejuízo na utilização desse mecanismo, pois o ato alcançou todas as finalidades que lhe são próprias e não gerou qualquer tipo de prejuízo para as partes (CARNEIRO, 2019, p. 238 e 239).

Todavia, referido entendimento no sentido da aplicabilidade do inventário extrajudicial para as hipóteses de existência de testamento do falecido, mesmo com os avanços acima indicados, ainda depende da via judicial para o registro do testamento ou obtenção da autorização do juízo competente para o processamento do testamento ou, ainda, sujeição da escritura pública de inventário à posterior homologação do juízo sucessório competente.

Isto porque, embora seja um procedimento de jurisdição voluntária, em que pode haver absoluto consenso entre as partes envolvidas, nosso ordenamento jurídico ainda exige provimento judicial para a abertura, registro e cumprimento de testamento, nos termos dos artigos 735737 do Código de Processo Civil.

Segundo Ribeiro:

A jurisdição voluntária, hoje consagrada como expressão doutrinária, em verdade, representa a administração pública de interesses privados.

Essa intervenção se justifica, mesmo na ausência de conflito entre as partes (que aqui são chamadas de interessados), porque em alguns casos, a lei estabelece, como condição de possibilidade para a efetivação do direito, que 
órgãos públicos sejam convocados para fiscalizar o cumprimento de determinado procedimento (RIBEIRO, 2019, p. 467).

No procedimento judicial o juiz verificará se o testamento contém seus requisitos formais, a inexistência de vício externo que o torne suspeito de nulidade ou falsidade (art. 735, CPC), ouvirá o Ministério Público e, não havendo dúvidas a serem esclarecidas, determinará o registro e cumprimento do testamento (art. 735, $2^{\circ}, \mathrm{CPC}$ ).

Mesmo dependendo do provimento judicial de abertura, registro e cumprimento do testamento ou de uma autorização do juízo competente para tanto, trata-se de um avanço para a desjudicialização, mormente tendo em vista que o procedimento relativo ao testamento tende a ser muito mais célebre do que o processamento de todo o inventário e partilha em juízo.

Por outro lado, a alternativa consistente em submeter o inventário extrajudicial a posterior homologação do juízo sucessório competente, na hipótese de existência de testamento, configura uma solução contraproducente, visto que provavelmente aludido trâmite processual será tão longo e dispendioso quanto o processamento do inventário judicial. Dificilmente os interessados optariam pela realização do inventário extrajudicial se tiverem que submetê-lo posteriormente a uma homologação judicial, o que implicará no dobro de despesas, restando, por consequência, inviável na prática.

Trata-se, indubitavelmente, de um importante passo no caminho da desjudicialização, mas urge salientar que muito ainda pode ser percorrido no que diz respeito às atividades que podem ser desempenhadas pelos notários e registradores. Neste sentido pode-se caminhar, inclusive, para a completa delegação do procedimento de abertura, registro e cumprimento do testamento para o tabelião de notas, com a participação do Ministério Público, desjudicializando totalmente o procedimento abordado no presente trabalho, possibilidade esta já levantada pela doutrina ${ }^{11}$ e objeto do Projeto de Lei $n^{\circ} 3799 / 2019$, de autoria da senadora Soraya Thronicke, em trâmite no Senado Federal. ${ }^{12}$

\footnotetext{
${ }^{11}$ Consoante argumentado por Érica Barbosa Silva e Fernanda Tartuce, “o legislador, porém, perdeu uma excelente oportunidade de ampliar as hipóteses do inventário extrajudicial ao deixar de prever tal possibilidade mesmo havendo testamento ou herdeiro incapaz. O advento da Lei $\mathrm{n}^{\circ}$ 11.441/07 permitiu a realização de inventários e partilhas com agilidade e segurança jurídica pelos Tabeliães de todo o Brasil, contribuindo para a desburocratização de procedimentos. Seria oportuna a ampliação desses atos também nas hipóteses em que o autor da herança tivesse deixado testamento ou herdeiro incapaz, desde que existisse consenso entre os herdeiros.
} 


\section{CONSIDERAÇÕES FINAIS}

Desta forma, como demostrado no decorrer do presente trabalho e considerando o objetivo inicialmente exposto, constata-se paulatinamente que as serventias extrajudiciais são um importante mecanismo para a desjudicialização e ampliação do acesso à justiça para a população, constituindo caminhos adequados para a solução de controvérsias e prevenção de litígios.

No que tange ao importante avanço de realizar os inventários e partilhas nas serventias notariais, o presente texto procurou apresentar uma contribuição teórica no sentido da valorização da interpretação sistemática e coerente do ordenamento jurídico como um todo. Buscou-se conjugar os dispositivos mencionados no presente trabalho e fortalecer a mudança de paradigma no sentido de consolidar a possibilidade da lavratura do inventário extrajudicial, mesmo com a existência de testamento do falecido, após o registro judicial do testamento ou com autorização do juízo competente.

A contribuição prática poderá vir à tona ao trazer-se a questão ao debate e, eventualmente, disparar mecanismos capazes de pôr termo, em definitivo, à controvérsia, tais como a regulamentação do tema pelo Conselho Nacional de Justiça, para ter validade em todo país; ou seu enfrentamento em eventual recurso repetitivo com efeitos erga omnes; ou, ainda, podendo ser objeto de uma alteração legislativa do artigo 610, caput, do Código de Processo Civil.

É importante revelar as limitações do presente estudo, tanto no seu aspecto teórico, visto que destinado à produção de um artigo científico e não a uma produção científica mais aprofundada e extensa, quanto em relação aos diversos obstáculos existentes para que a contribuição prática, acima referida, venha a se concretizar.

Nesses casos, o ato notarial poderia contar com a aquiescência do Ministério Público para a cautela dos interesses indisponíveis envolvidos (SILVA, 2016, p. 13/14).

${ }^{12}$ Segundo o Projeto de Lei no 3799/2019, o artigo 610 do CPC passaria a ter a seguinte redação: “Art. 610. Inexistindo acordo entre os herdeiros e os legatários, proceder-se-á ao inventário judicial. $\S 1^{\circ}$ Se todos os herdeiros e os legatários forem concordes, o inventário e a partilha poderão ser feitos por escritura pública, a qual constituirá documento hábil para qualquer ato de registro, bem como para levantamento de importância depositada em instituições financeiras. $\S 3^{\circ}$ Se houver herdeiro incapaz ou testamento, a eficácia da escritura pública dependerá de anuência do Ministério Público. $§ 4^{\circ}$ Com a discordância do Ministério Público, o tabelião de notas não lavrará a escritura e o inventário será judicial." 
Contudo, nos dizeres de Silva e Tartuce, "para poderem atingir o desiderato de se tornarem caminhos viáveis para o efetivo acesso à justiça, os meios extrajudiciais devem não apenas ser estimulados pelas normas como também terem seus entraves removidos pelos intérpretes" (SILVA, 2016, p.23).

Assim, enquanto a normativa legislativa se desenvolve a passos mais lentos, é preciso valorizar a doutrina especializada e as decisões judiciais fundamentadas na interpretação sistemática e teleológica do ordenamento jurídico como um todo, os quais, em seus papéis de intérpretes e por meio de suas construções teóricas, tanto contribuem para a mudança de paradigmas e evolução da ciência do Direito.

\section{REFERÊNCIAS}

ASSOCIAÇÃO DOS NOTÁRIOS E REGISTRADORES DO BRASIL (ANOREG-BR). Cartório em números. $2^{a}$ edição, 2020. Disponível em: https://www.anoreg.org.br/site/wpcontent/uploads/2020/11/Cart\%C3\%B3rios-em-N\%C3\%BAmeros-2edi\%C3\% A7\%C3\%A3o2020.pdf. Consulta realizada em 03 fev. 2021.

BRASIL. Lei no 10.406, de 10 de janeiro de 2002. Institui o Código Civil. Brasília, DF: Presidência da República, 2002. Disponível em: L10406compilada (planalto.gov.br). Consulta realizada em 03 fev. 2021.

Lei $\mathbf{n}^{0}$ 11.441, de 04 de janeiro de 2007. Altera dispositivos do Código de Processo Civil, possibilitando a realização de inventário, partilha, separação consensual e divórcio consensual por via administrativa. Brasília, DF: Presidência da República, 2007. Disponível em: Lei no 11.441 (planalto.gov.br). Consulta realizada em 03 fev. 2021.

Lei no 13.105, de 16 de março de 2015. Institui o Código de Processo Civil. Brasília, DF: Presidência da República, 2015. Disponível em: http://www.planalto.gov.br/ccivil_03/_ato2015-2018/2015/lei/113105.htm. Consulta realizada em 03 fev. 2021.

Decreto-Lei no 4.657, de 04 de setembro de 1942. Institui a Lei de Introdução às Normas do Direito Brasileiro. Brasília, DF: Presidência da República. Disponível em: Del4657compilado (planalto.gov.br). Consulta realizada em 03 fev. 2021.

Conselho Nacional de Justiça. Resolução no 35, 24 de abril de 2007.

Disciplina a lavratura dos atos notariais relacionados a inventário, partilha, separação consensual, divórcio consensual e extinção consensual de união estável por via administrativa. Brasília, DF: Conselho Nacional de Justiça, 2007. Disponível em: compilado172958202007015efcc816b5a16.pdf (cnj.jus.br). Consulta realizada em 02 fev. 2021. 
Superior Tribunal de Justiça. Recurso Especial no 1.808.767-RJ. $4^{\mathrm{a}}$

Turma. Relator Ministro Luís Felipe Salomão. Julgamento em 15/10/2019. Disponível em: Revista Eletrônica (stj.jus.br). Consulta realizada em 06 fev. 2021.

Conselho da Justiça Federal. Enunciados da I Jornada de Direito

Processual Civil. Brasília/DF: Conselho da Justiça Federal, Centro de Estudos Judiciários, 2017. Disponível em: https://www.cjf.jus.br/cjf/corregedoria-da-justica-federal/centro-deestudos-judiciarios-1/publicacoes-1/i-jornada-de-direito-processual-civil. Consulta realizada em 02 fev. 2021.

Conselho da Justiça Federal. Enunciados da I Jornada sobre Prevenção e Solução Extrajudicial de Litígios. Brasília/DF: Conselho da Justiça Federal, Centro de Estudos Judiciários, 2016. Disponível em: https://www.cjf.jus.br/cjf/corregedoria-da-justicafederal/centro-de-estudos-judiciarios-1/prevencao-e-solucao-extrajudicial-de-litigios. Consulta realizada em 02 fev. 2021.

Conselho da Justiça Federal. Enunciados da VII Jornada de Direito Civil. Brasília/DF: Conselho da Justiça Federal, Centro de Estudos Judiciários, 2015. Disponível em: https://www.cjf.jus.br/cjf/corregedoria-da-justica-federal/centro-de-estudosjudiciarios-1/publicacoes-1/jornadas-cej/vii-jornada-direito-civil-2015.pdf. Consulta realizada em 02 fev. 2021.

CAPPELLETTI, Mauro; GARTH, Bryant. Acesso à justiça. Tradução de Ellen Gracie Northfleet. Porto Alegre: Fabris, 1988.

CARNEIRO, Paulo Cezar Pinheiro. Inventário e partilha: judicial e extrajudicial. Rio de Janeiro: Forense, 2019.

COLÉGIO NOTARIAL DO BRASIL. Enunciados do XIX Congresso Brasileiro de Direito Notarial e Registral. Salvador/BA: Colégio Notarial do Brasil, 2014. Disponível em: https://www.26notas.com.br/blog/?p=9754. Consulta realizada em 02 fev. 2021.

HILL, Flávia Pereira. Mediação nos Cartórios Extrajudiciais: desafios e perspectivas. In: Revista Eletrônica de Direito Processual - REDP. Volume 19. Set-Dez 2018. Disponível no endereço eletrônico: www.redp.uerj.br. Consulta realizada em 02 fev. 2021.

INSTITUTO BRASILEIRO DE DIREITO DE FAMÍLIA. Enunciados do X Congresso Brasileiro de Direito de Família. Belo Horizonte/MG: Instituto Brasileiro de Direito de Família, 2015. Disponível em:

https://flaviotartuce.jusbrasil.com.br/noticias/249895741/enunciados-ibdfam-X-congressobrasileiro-de-direito-de-familia. Consulta realizada em 02 fev. 2021.

RIBEIRO, Marcelo. Processo Civil. 2. ed. Rio de Janeiro: Forense. São Paulo: Método, 2019.

SILVA, Érica Barbosa; TARTUCE, Fernanda. O novo CPC e os atos extrajudiciais cartoriais: críticas, elogios e sugestões. In: Revista Magister de Direito Civil e Processual Civil.

Volume 12. Número 71. Porto Alegre: Lex, março/abril de 2016. Disponível em: O-Novo- 
CPC-e-as-Atividades-Extrajudiciais-Erica-e-Fernanda.pdf (spcm.com.br). Consulta realizada em 02 fev. 2021.

TARTUCE, Flávio. Inventário Extrajudicial com Testamento. Disponível em: Inventário Extrajudicial com Testamento (jusbrasil.com.br). Consulta realizada em 06 fev. 2021.

WATANABE, Kazuo. Acesso à justiça e meios consensuais de solução de conflitos. In: Visão multidisciplinar das soluções de conflitos no Brasil. Coordenação de João Gradino Rodas, Aline Anhezini de Souza, Juliana Poloni, Guilherme Bertipaglia Leite da Silva e Eduardo Machado Dias. $1^{\circ}$ ed. Curitiba: Editora Prismas, 2018. 